\title{
Cognitive and functional impairment in elderly of an isolated community of slaves' descendents in Brazil
}

Danielly Bandeira Lopes ${ }^{1}$, Leonardo Caixeta²

1: Federal Institute of Goias, 2: Federal University of Goias

Background: The frequency of diseases related to aging, such as dementia, increases with age, which constitutes a major public health problem in the future, especially in developing countries. The main changes observed in demented elderly refer to cognitive and functional aspects which have strong correlation. The aim of this study was to estimate the prevalence of cognitive and functional impairment of elderly residents of an isolated community of slaves' descendents, remaining Quilombo, located in the northeastern state of Goias-Brazil, called Kalunga. Methods: It was a cross-sectional study with noninvasive methods, based on primary data of cognitive and functional elderly aged above 60 years of quilombo Kalunga, in the northeastern state of Goias-Brazil (Figure 1). Were collected and analyzed data to identify (age, sex), sociodemographic factors (education, place), cultural and previous morbidities (hypertension, diabetes) participants through semi-structured questionnaire. Data on cognitive and functional assessment were obtained by applying the Mini-Mental State Examination (MMSE) and the Functional Activities Questionnaire (FAQ), respectively. Results: A total of 65 elderly were evaluated. Most of them were male $(52.3 \%)$, married $(58.5 \%)$, illiterate $(93.8 \%)$ and mean age of 71.58 years, ranging between 60 and 93 years. The prevalence of individuals with cognitive and functional impairment was $9.2 \%(n=6)$, and the functional impairment (18.5\%) was more prevalent than cognitive (12.3\%). The mean values of the MMSE and FAQ were respectively 18.83 and 4.03 points. There was a negative correlation between these variables $(-0.581)$. Table 2 provides data regarding the mean, standard deviation and minimum and maximum values of the MMSE and FAQ. Conclusion: The prevalence rate of cognitive and functional impairment detected in this study was low compared to other studies conducted in Brazil, but was similar to studies in other populations.

\begin{tabular}{|c|c|c|}
\hline Variables & $n$ & $\%$ \\
\hline $\begin{array}{lll}\text { Mean age } & (\mathrm{sd}) \\
71.58(8.17) & \end{array}$ & 65 & \\
\hline \multicolumn{3}{|l|}{ Age group } \\
\hline $60-64$ & 14 & 21.5 \\
\hline $65-69$ & 17 & 26.2 \\
\hline $70-74$ & 8 & 12.3 \\
\hline $75-79$ & 17 & 26.2 \\
\hline $80-84$ & 4 & 6.2 \\
\hline$\geq 85$ & 5 & 7.7 \\
\hline \multicolumn{3}{|l|}{ Gender } \\
\hline Male & 34 & 52.3 \\
\hline Female & 31 & 47.7 \\
\hline \multicolumn{3}{|l|}{ Marital status } \\
\hline Married & 38 & 58.5 \\
\hline Single & 5 & 7.7 \\
\hline Divorced & 5 & 7.7 \\
\hline Widower & 17 & 26.2 \\
\hline \multicolumn{3}{|l|}{ Literate } \\
\hline Yes & 4 & 6.2 \\
\hline No & 61 & 93.8 \\
\hline
\end{tabular}

Table 1: Sociodemographic characteristics of the sample of the study population.

\begin{tabular}{|l|l|l|}
\hline & MMSE & FAQ \\
\hline Mean & 18.83 & 4.03 \\
\hline $\begin{array}{l}\text { Standard } \\
\text { deviation }\end{array}$ & 3,99 & 6,22 \\
\hline Minimum & 1 & 0 \\
\hline Maximum & 26 & 30 \\
\hline
\end{tabular}

Table 2: Mean, standard deviation and minimum and maximum values of the MMSE and FAQ.

Sources:

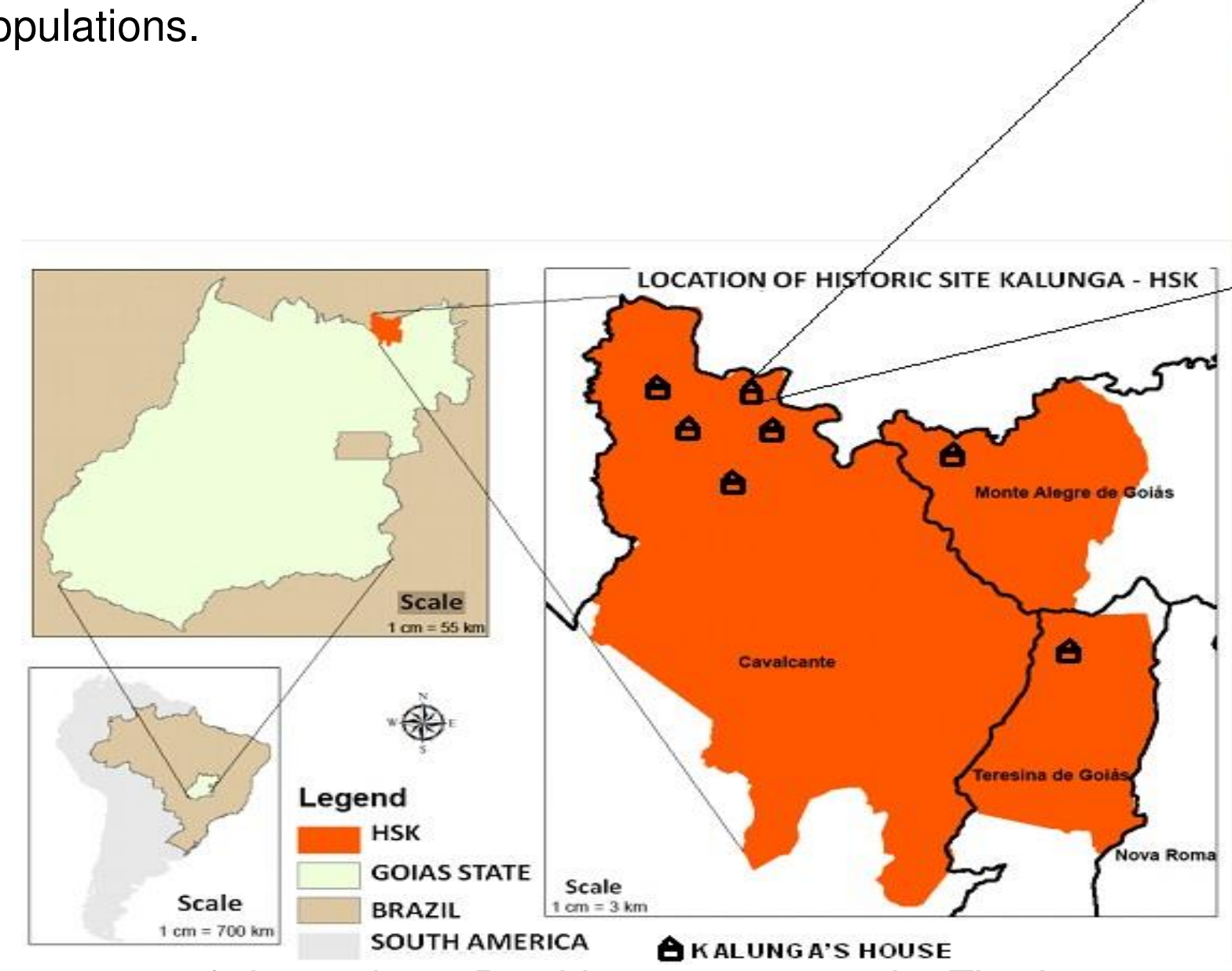

Ferri et al. Global prevalence of dementia: a Delphi consensus study. The Lancet, 2005;

Uwakwe $\mathrm{R}$ et al.The Epidemiology of Dependence in Older People in Nigeria: Prevalence, Determinants, Informal Care, and Health Service Utilization. A 10/66 